\title{
Form follows function
}

\author{
Tirone E. David, MD
}

\author{
From the Division of Cardiovascular Surgery, Peter Munk Cardiac Centre at Toronto General Hospital, and Uni- \\ versity of Toronto, Toronto, Ontario, Canada \\ Disclosures: Author has nothing to disclose with regard to commercial support. \\ Received for publication Feb 16, 2017; accepted for publication Feb 16, 2017; available ahead of print March 27, \\ 2017. \\ Address for reprints: Tirone E. David, MD, 200 Elizabeth St, 4N453, Toronto, Ontario, M5G 2C4, Canada \\ (E-mail: tirone.david@uhn.ca). \\ J Thorac Cardiovasc Surg 2017;153:1261-2 \\ $0022-5223 / \$ 36.00$ \\ Copyright (c) 2017 by The American Association for Thoracic Surgery \\ http://dx.doi.org/10.1016/j.jtcvs.2017.02.046
}

The architecture phrase "form follows function" is also applicable in biology where anatomic structures evolved according to what they are meant to do. Thus, the anatomy of the aortic root represents the optimal form to fulfill its function. Chronic disorders that alter the function of the aortic valve may eventually cause anatomic alterations in the aorta. Poststenotic dilatation of the ascending aorta in patients with aortic stenosis has been diagnosed for a long time. ${ }^{1}$ The advent of newer techniques of imaging the heart and great arteries such as echocardiography, computerized tomography, and magnetic resonance imaging (MRI), as well as the constantly expanding knowledge of genetics have helped us to understand the processes that cause dilatation of the aorta associated with aortic valve disease. Longstanding flow disturbances caused by stenosis of a once-normal tricuspid aortic valve can cause significant dilatation of the aorta. $^{2}$ Gaudino and colleagues ${ }^{2}$ described a series of 93 patients with tricuspid aortic valve stenosis and ascending aortic aneurysm of 50 to $59 \mathrm{~mm}$ (mean, $56 \pm 2 \mathrm{~mm}$ ) who were treated with isolated aortic valve replacement, and after a mean follow-up of $14.7 \pm 4.8$ years not a single patient had died of aorta-related complications and the size of the aneurysms did not change significantly. If this observation is correct, the flow disturbance caused by stenosis of a tricuspid aortic valve was corrected by aortic valve replacement and the process that caused dilatation of the aorta was arrested. We have always replaced an ascending aorta of 50 to $59 \mathrm{~mm}$ at the time of aortic valve replacement regardless of the aortic valve pathology, and we have evidence that it must be done in patients with bicuspid aortic valve (BAV). ${ }^{3}$

BAV disease includes a heterogeneous group of anatomic abnormalities of the aortic valve that may be associated with dilatation of the aortic root, ascending aorta, and proximal aortic arch. ${ }^{4,5}$ The genetic determinants of BAV and its associated aortopathy remain poorly defined largely because its genetic origins are even more heterogeneous than its phenotypes. Not only have clinical correlations between the various BAV phenotypes and the site and extensiveness of the aortopathy been made, ${ }^{4,5}$ but lately time-resolved 3-dimensional MRI studies on blood flow

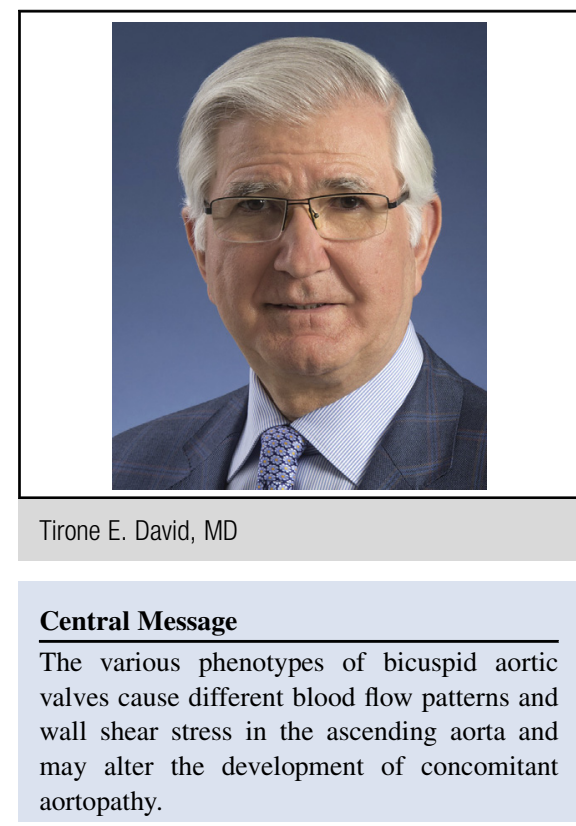

See Article page 1263.

disturbances (4D flow MRI) have improved our knowledge of the relationship between the various morphologic types of cusp fusion and its effect on the proximal thoracic aorta. ${ }^{6}$

Shan and colleagues from Shanghai, China, ${ }^{7}$ further expanded our knowledge of BAV and its effect on the arterial wall by examining wall shear stress (WSS) in patients with normal aortic valve, BAV without valve dysfunction, and BAV with stenosis and insufficiency using 4D flow MRI. $^{7}$ The patients were matched for age and size of ascending aorta, and 15 had normal tricuspid aortic valve, 20 had BAV without significant valve dysfunction, 15 had BAV with aortic stenosis (AS), and 15 had BAV with aortic insufficiency (AI). ${ }^{7}$ All BAV patients had fused right and left cusps and the dilatation of the aorta was mild $(\sim 40 \mathrm{~mm})$ in all patients. 4D flow MRI of normal aortic valves showed a central flow jet and cohesive, whereas in normally functioning BAV the flow was eccentric with helical streamlines extending from the aortic root to the origin of aortic arch. WSS in the proximal half of the ascending aorta was lower in patients with tricuspid aortic valve than in patients with normally functioning BAV, and WSS was further increased in patients with AS or AI. The pattern of flow in the ascending aorta in patients with AI was like that of normally functioning BAV, albeit elevated due to increased stroke volume and very different in AS where highly eccentric velocity distribution was observed. 
The increased WSS in patients with BAV probably accelerates the degenerative process in the aorta, particularly in patients with AI because of the increased stroke volume. However, we believe that when patients with BAV need surgery because of aortic valve dysfunction or dilatation of the aorta, the current guidelines remain pertinent. If the BAV is functioning well, surgery should be considered when the diameter of the ascending aorta reaches $55 \mathrm{~mm}$ or the aortic root reaches $50 \mathrm{~mm}$. In these circumstances, the native BAV can often be preserved. If the indication for surgery is a dysfunctional aortic valve, AI, or AS, we believe that the ascending aorta should be replaced if its diameter is $\geq 45 \mathrm{~mm}$. $^{3}$ Concomitant dilatation of the aortic root in these cases (BAV with fusion of right and left cusp) is often asymmetrical and the coronary artery orifices are close to the aortic annulus, and we do not believe that is necessary to replace the entire aortic root. Replacement of the ascending aorta and posterior aortic sinus is adequate during aortic valve replacement, particularly when a bioprosthetic aortic valve is used.

\section{References}

1. Tricomi G. Calcified aortic valve stenosis with post-stenotic dilatation of the ascending aorta. Radiol Med. 1952;38:843-8.

2. Gaudino M, Anselmi A, Morelli M, Pragliola C, Tsiopoulos V, Gileca F, et al. Aortic expansion rate in patients with dilated post-stenotic ascending aorta submitted only to aortic valve replacement long-term follow-up. J Am Coll Cardiol. 2011;58:581-4.

3. Borger MA, Preston M, Ivanov J, Fedak PW, Davierwala P, Armstrong S, et al. Should the ascending aorta be replaced more frequently in patients with bicuspid aortic valve disease? J Thorac Cardiovasc Surg. 2004;128: 677-83.

4. Fazel SS, Mallidi HR, Lee RS, Sheehan MP, Liang D, Fleishman D, et al. The aortopathy of bicuspid aortic valve disease has distinctive patterns and usually involves the transverse aortic arch. J Thorac Cardiovasc Surg. 2008;135:901-7.

5. Sievers HH, Stierle U, Hachmann RM, Charitos EI. New insights in the association between bicuspid aortic valve phenotype, aortic configuration and valve haemodynamics. Eur J Cardiothorac Surg. 2016;49: 439-46.

6. Stephens EH, Hope TA, Kari FA, Kvitting JP, Liang DH, Herfkens RJ, et al. Greater asymmetric wall shear stress in Sievers' type 1/LR compared with 0/LAT bicuspid aortic valves after valve-sparing aortic root replacement. J Thorac Cardiovasc Surg. 2015;150:59-68.

7. Shan Y, Li J, Wang Y, Wu B, Barker AJ, Markel M, et al. Aortic shear stress in bicuspid aortic valve in patients with stenosis and insufficiency. $J$ Thoracic Cardiovasc Surg. 2017;153:1263-72.e1.

Access to The Journal of Thoracic and Cardiovascular Surgery Online is reserved for print subscribers!

Full-text access to The Journal of Thoracic and Cardiovascular Surgery Online is available for all print subscribers. To activate your individual online subscription, please visit The Journal of Thoracic and Cardiovascular Surgery Online, point your browser to http://www.mosby.com/jtcvs, follow the prompts to activate your online access, and follow the instructions. To activate your account, you will need your subscriber account number, which you can find on your mailing label (note: the number of digits in your subscriber account number varies from 6 to 10 ). See the example below in which the subscriber account number has been circled:

\section{Sample mailing label}

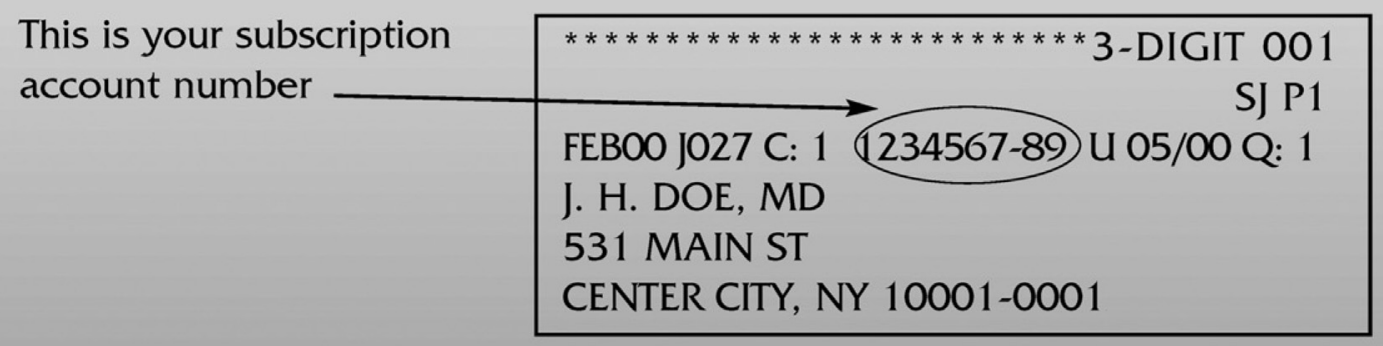

Personal subscriptions to The Journal of Thoracic and Cardiovascular Surgery Online are for individual use only and may not be transferred. Use of The Journal of Thoracic and Cardiovascular Surgery Online is subject to agreement to the terms and conditions as indicated online. 